\title{
ESCALATING RATES OF CRIME AND CRIMINALITY: ROLE OF THE MEDIA IN CRIME MANAGEMENT
}

\author{
Prof. Chinyere Stella Okunna \\ Department of Mass Communication, \\ Nnamdi Azikiwe University, Awka \\ 08033364322 \\ cs.okunna@unizik.edu.ng
}

\begin{abstract}
The rates of crime and criminality are escalating in many parts of the world, particularly in Nigeria. The power and centrality of the media make them indispensable in whatever crime management actions that are being taken to arrest the worsening security situation and escalating crime rate in Nigeria. This paper is a discourse which highlights, against the backdrop of the prevalence of crime and criminality in contemporary Nigeria, the role of a professional media system as a major factor that can help mitigate crime and criminality in the country. Undoubtedly, responsible and professionally-oriented media can do a lot of good in crime management, and the media should rise to the occasion in the effort to arrest the present precarious situation.
\end{abstract}

Keywords: Crime, Criminality, Crime management, Peace, Media

\section{SETTING THE SCENE: THE WORSENING CRIME SITUATION}

There are clear indications that the rates of crime and criminality are escalating in many parts of the world. Using Nigeria as a microcosm of countries plagued by such deplorable situations, it has become common knowledge that the security situation in this country is worsening by the day, and that the crime rate is rising to an all-time high. From North to South, East to West, in all six Geopolitical Zones, crime and criminality are apparently taking over the country. According to Nigeria 2020 Crime \&Safety Report of the United States Consulate, Lagos (2020):

$>$ The current U.S. Department of State Travel Advisory assesses Nigeria at Level 3, indicating travelers should reconsider travel to Nigeria due to crime.

$>$ There is a wide range of violent crimes in the country, including armed robbery, assault, burglary, carjacking, rape, kidnaping, extortion, fraud etc.

$>$ "Do not travel to Bornu and Yobe States and Northern Adamawa State due to terrorism; Adamawa, Bauchi, Bornu, Gombe, Kaduna, Kano, and Yobe States due to kidnapping; and Coastal areas of Akwa Ibom, Bayelsa, Cross Rivers, Delta, and Rivers (with the exception of Port Harcourt) due to crime, civil unrest, kidnapping, and maritime crime."

$>$ "Crime is rampant throughout southern Nigeria, particularly the Niger Delta region...."

"...mainland portion of Lagos has experienced periodic outbreaks of violence among localized street gangs known as "Area Boys." 
Volume 1 Number 1 Maiden Issue

$>$ "Multiple armed criminal elements exist throughout Nigeria, ranging from low level to organized syndicates."

$>$ Cultist or gang violence, which often erupts in supremacy battles between various groups, is a concern.

Cybercrime has become a concern and is becoming more sophisticated.

The situation is becoming more and more terrifying. A typical example is the increasing rate of violent crimes against women, particularly rape. As documented by Premium Times (2020):

\begin{abstract}
Rising cases: The past couple of weeks was filled with horrendous tales of young girls being raped across the country. PREMIUM TIMES reported the cases of Vera Omozuwa in Edo State and Barakat Bello in Oyo State, both of whom died from the assault. This paper also reported how a twelve-year-old girl in Ajah, Lagos, was raped by four masked men in her home.... No fewer than 80 rape cases were recorded in various parts of Anambra State during the COVID-19 lockdown between April and May.
\end{abstract}

In the face of the incessant slaughtering of Christians in Northern Nigeria, Revd Edward Obumneme Joseph (2020), in his lamentation on Facebook titled "CALL FOR MEDIA ACTION", reveals the following horrifying situation: "107 killed in Kajuru, Kaduna State, 82 people killed in Bornu, 70 souls wasted in Sokoto, 60 lives terminated in Katsina, total of 319 deaths from same people all within one week!"

Indeed, given the power and ubiquity of the media in the modern world, media action is urgently needed to support whatever other crime management actions that are being taken to arrest the worsening security situation and escalating crime rate in Nigeria.

\title{
THE POWER OF THE MEDIA
}

It is incontrovertible that in this 'Information Society' of the $21^{\text {st }}$ century, the media function as the most powerful tools for the dissemination of information - a function on which many other crucial functions of the media are predicated. This is probably because people no longer interact to the extent they used to, resulting to increased dependence on the media for news, views, information, enlightenment, education and even guidance on an astounding variety of issues and events. In fact, whether it is the 'traditional' mass media of radio, television and newspapers, or the new social media, the media are waxing stronger and stronger in their ability to provide information simultaneously to a vast, heterogeneous and scattered audience. Nkwocha (2016) refers to this power of the media when he states that "The mass media, as organs of information dissemination to very large and heterogeneous audiences, have tremendous power and influence in shaping public opinion and perception." Expressing a similar view of the power of the media, Okunna and Omenugha (2012) emphasize the indispensability of the media in the affairs of modern societies:

There is absolutely no doubt that, in the modern world, the mass media possess incredible power at the information level. ...the mass media have the marvelous ability to reach millions, to raise issues, to create awareness on topics and to disseminate information with great efficiency.

With the advent of the social media and all forms of Information and Communication Technologies (ICT), the media have become even more powerful and important in human communication by changing the way information flows because social media, according to Sevigny (2015) have: 
$>$ shattered the linear communication model by introducing the concept of usergenerated content;

$>$ introduced instant feedback into the structure, thus making ...[communication] more dialogical and interpersonal.

The strategic importance of online communication in the modern world is similarly underscored by Nkwocha (2016) as follows:

As a result of the internet, most media outputs are now released online, meaning that they can be read or viewed from anywhere in the world through the internet. This makes the news media much more powerful in influencing public opinion and perception.

\section{ROLE OF THE MEDIA IN SOCIETY}

Given their incredible power, it is not surprising that the media have the capacity to perform a wide variety of functions in the society, both at the individual and societal levels, including:

$>$ Information

$>$ Education

$>$ Entertainment

$>$ Advertising

$>$ Socialization

$>$ Promotion of culture

$>$ Motivation and Mobilization

$>$ Integration

$>$ Provision of a platform for public debate and discussion which ultimately lead to the formation of public opinion.

Through the media's unique characteristics and the professionalism of the variety of people who work in the various mass media, the media are well positioned to perform their numerous functions in society and have various effects on individuals or the society as a whole.

Several theories and theoretical approaches of media effects have argued convincingly that, under varying circumstances, the media can exert tremendous influence as moulders of society and have the capacity to determine, to varying degrees, how media audiences react to particular issues and events, or how they perceive social reality generally. Some of these theories/theoretical orientations explain the power of the media in agenda-setting, statusconferral, and framing.

\section{Agenda-Setting Theory of the Mass Media}

According to the Agenda-setting Theory, the media have the capacity to influence what members of the society think about and consider important. This theory explains the ability of the media "to influence the salience [importance] of topics on the public agenda ... [and] if a news item is covered frequently and prominently, the audience will regard it as more important" (Wikipedia).Consequently, public discussions, and ultimately public opinion, tend to follow the headlines because the media are able to tell people what to think about through their agenda-setting function - by placing certain topics on the media agenda. 


\section{Media and Status-Conferral}

Agenda-setting goes hand in hand with status-conferral through which the media confer legitimacy and importance on people, issues and events, simply by reporting them - thus making they appear 'right' and important.

\section{The Framing Theory of the Media}

Framing Theory is very closely related to the Agenda-setting Theory. In fact, they are so closely related that Framing Theory is actually regarded as an adaptation of Agenda-setting Theory. However, framing is a step beyond agenda-setting because while agenda-setting tells us what (the things) to think about, framing tells us what to think about those things. This close relationship can easily be seen in the explanation of Framing Theory:

Agenda setting theory just tells what to think about but framing theory tells how to think about the information. So framing theory is also known as second level agenda setting theory ... Fram[ing] influences the mindset (perception) of people and impacts their decision making on the topic (Google).

\section{CRIME AND THE MEDIA: ROLE OF THE MEDIA IN CRIME MANAGEMENT}

In its most basic definition, 'crime' refers to "activities that involve breaking the law" (Hornby, 2015), and 'crime management', which has to do with crime prevention, is concerned with efforts to reduce and prevent crime, and usually, such efforts are mostly made by governments/law enforcement officials. For any meaningful discussion of the role of the media in crime management, the following questions are pertinent:

$>$ What is the relationship between media and crime?

$>$ Why are the media so fascinated with crime and deviance?

$>$ Is the media's obsession with crime harmful?

$>$ What influence do the mass media have on public perceptions of crime?

$>$ How do the mass media influence crime?

$>$ How can the media help in crime prevention and creation of a crime-free peaceful society?

Although the media are well positioned to perform a wide variety of functions in society, it is generally believed that the role of the media is particularly powerful and virtually indispensable in contemporary society in their functions of information, mobilization, motivation, and provision of a forum or platform for public debate/discussion/formation of public opinion. Understandably, therefore, the media can play a very crucial role in crime management by performing these functions in specialized ways.

\section{Information}

As in other aspects of life generally, the mass media are increasingly serving as the primary public source of crime information, so much so that the reporting of crime and violence has become a primary preoccupation of the media. However, in performing this function, the media have been accused of sensationalism, as well as being obsessed with crime and criminality, by allowing economic and marketing considerations to shape their reporting of crime because the media are profit-oriented, and crime sells. Because of the nature of crime and the tendency of the mass media to seek out and report such negative and 'newsworthy' 
situations, the media are obsessively attracted to crime and criminal activities. Consequently, both the nature and extent of crime in society could become exaggerated. Thus, apart from the news content, the contents of film, television and computer technologies have become awash with images of crime and violence. This general media obsession with crime is believed to be making the public perceive the society as unsafe and leaving them alarmed and anxious about public safety. There is even a more alarming situation in the social media where, as a result of the 'gatelessness' of online media platforms, all manner of information on crime and criminality could be accessed by social media users, including fully illustrated step-by-step tutorials on bomb-making and how to commit the perfect murder!!!

Conversely, particularly in developing countries like Nigeria, the media have also been accused of under-reporting crime by succumbing to propagandist tendencies of government information managers who (for whatever reasons) contrive through unethical media relations to create a false impression of a secure, crime-free society. This scenario could compromise public safety, and handicap crime management efforts, by making the public complacent, and thus vulnerable to the activities of criminals.

Overall, as information brokers, the media should serve as a strong partner in crime management, in line with the following:

- The media's access to sources of information and capacity to gather, package and disseminate crucial information, particularly through investigative journalism, should be a great asset in crime management. Such information should be indispensable to crime management officials who should gain access to the information through effective media relations which is concerned with:

working with media for the purpose of informing the public of an organization's mission, policies and practices in a positive consistent and credible manner. Typically, this means coordinating directly with the people responsible for producing the news and features in the mass media (Wikipedia, emphasis added).

Nkwocha (2009) defines media relations as:

\begin{abstract}
The strategic public relations function which establishes and maintains mutual understanding, goodwill, cooperation, respect and support between an organization and the mass media practitioners/owners with the aim of achieving maximum positive publicity, media support, as well as well-defined corporate and public relations objectives.
\end{abstract}

Media relations is a specialized function of Public Relations (PR) and should best be handled by a PR professional in the crime management team. In fact, effective media relations is particularly crucial for effective crime management in a country like Nigeria where the image and reputation of law enforcement and crime management officials are of primary importance. For whatever reason(s), the image and reputation of these officials are generally poor among Nigerians, and require drastic improvement in order for them to gain the confidence and support of the public; this should contribute to successful crime management. Generally, reputation management, image management, and branding have to do with "managing the image and reputation of important organizations and governments" (Nkwocha, 2016), and are core components of Public Relations which itself is a strategic communication process. Consequently, the role of the media becomes indispensable in all of these. 
- Through their agenda-setting and status-conferral functions, the media should place crime management high on the media agenda, and therefore societal agenda, through crime reporting. However, the provision of crime information should be strictly guided by professional ethics to avoid the two extremes of over-reporting and sensational reporting on one hand, and propagandist under-reporting or suppression of relevant information on the other hand. In terms of crime management, as explained earlier, one extreme creates fear and anxiety in the society while the other extreme generates complacency, which is equally unhealthy for society.

By giving so much attention to crime and crime-related issues, as pointed out above in Section 3.1, the media are strategically positioned to play a role that can either promote crime management or escalate crime in society. The role of the media in crime management therefore depends on how the media deal with crime and criminality when, for whatever unfortunate reasons, they occur in the society. However, for the media to play a positive role in support of crime management, they must function in the tradition of a peace media system, through frequent and prominent coverage of people and issues that promote a crime-free society. This is in line with what Okunna and Popoola (2017) say about the role of the media in achieving a peaceful society generally by a peace media system "whose cultural dynamics is oriented towards peacefulness [and] can work towards the enthronement of a culture of peace." In performing this crucial agenda-setting function, the media should be guided by professional journalistic ethics.

Professional ethics is also necessary as a check on the power of the media in their status-conferral function. This is particularly necessary in our type of society where media attention often glamorizes or eulogizes wealthy or influential people in society, thus conferring high status and importance on them, even when they are known to have acquired their wealth through fraudulent or criminal activities.

\section{Mobilization and Motivation}

The media can also play a strong role in crime management through mobilization and motivation. As Okunna and Omenugha (2012) clearly state, in performing these functions, the role of the media should be:

to encourage and ginger people up to achieve the aims or goals of the society. These goals are promoted by the media which then stimulate and foster the aspirations and activities of individuals and communities to achieve such goals.

Through their 'agenda-setting' and 'framing' functions, the media could place crime management on the public agenda as important issues worthy of government attention and action. Similarly, the public and other stakeholders could be motivated and mobilized for collaboration and positive action towards effective crime management. By drawing attention to behavior that is generally perceived as acceptable, and by exposing and condemning behavior that is criminal, the media can raise public awareness, activate anti-crime values, and generate outside pressure from the public against crime.

Ultimately, the way the media 'frame' crime, crime-related issues and the desirability of a crime-free society could influence people's perception or mindset, determine their decisionmaking on crime and criminality, and be a major factor in enthroning a zero crime-tolerance 
culture among Nigerians. Obviously, a media system that glamorizes crime is totally incapable of achieving this purpose!

\section{Provision of Forum or Platform for Public Debate/Discussion and Formation of Public Opinion}

Public opinion has to do with what the majority of people in a society think about a particular issue of public importance. Given their characteristics, the mass media are quite effective in shaping public opinion. This they do by providing a platform through which people can express their opinion and through which they can know what others are thinking about the issue under discussion, and consequently arrive at the aggregate opinion on the issue. This is one of the most fundamental functions of the media in a democracy.

This important function could be applicable to crime management. The media could create awareness on crime and crime-related issues, orchestrate and coordinate public discussion about them, and serve as the platform through which public opinion is crystalized on such issues. This ultimate widespread or popular opinion on crime and crime-related issues could guide public, government and law enforcement decisions and actions in support of crime management.

\section{CONCLUSION}

Virtually all human experience today is mediated/media-centric experience, thus placing the wide variety of media channels right at the centre of all human activities. Activities like crime management and law enforcement are particularly media-centric, and their effectiveness is dependent on access to the media and proper utilization of mediated information. The media do not only raise public awareness about crime, its causes, consequences and possible remedies, but they also investigate and report incidents of crime, thereby supporting individuals and organizations who have the responsibility of crime management.

In this age of convergence, therefore, effective crime management requires crime management professionals to:

$>$ Be knowledgeable about the various media channels and platforms

$>$ Be abreast with trends in media literacy, and

$>$ Be conversant with the workings of the various media, including the social media.

In fact, effective crime management should be anchored on effective information management which is guaranteed by the capacity to access and utilize information from both the 'traditional' mass media channels and the social media/new media. Thus, for the media to play an effective role in crime management there should be effective information management by crime management professionals, which will ultimately depend on effective media relations.

Finally, because in today's world, people are now on social media, crime management officials must have a presence on these new media. Social media are primarily Internet- and mobile-based tools and are becoming the most dominant tools for sharing and discussing information among human beings in the modern world. In fact, anybody who has crime management responsibilities today but lacks a good knowledge of or access to or presence on the social media, is dangerously unqualified for his/her job!!! 


\section{REFERNCES}

Hornby, A.S. (2015). Oxford Advanced Learners' Dictionary, New $8^{\text {th }}$ Edition. Oxford: UniversityPress.

Joseph, E.O. (2020). “CALL FOR MEDIA ACTION”. Facebook, 13thFebruary, 2020.

Nkwocha, J. (2016). Reputation Management \& Branding. Port Harcourt: Biz Pages Publishing \& Printing Company Limited.

Nkwocha, J. (2009). “A New Model in Community Relations Practices in the Niger Delta: A Case Study of EPCL and its Host Communities", Presentation for the Award of Fellow of NIPR.

Okunna, C.S. and Omenugha, K.A. (2012). Introduction to Mass Communication, $3^{\text {rd }}$ Edition. Enugu: New Generation Books.

Okunna, C.S. and Popoola, M. (2017). "Role of the Media in Building a Culture of Peace". In U.A. Pate and L. Oso (eds), Multiculturalism, Diversity and Reporting Conflict in Nigeria. Ibadan: Evans Brothers (Nigeria Publishers) Limited.

Premium Times, 13 ${ }^{\text {th }}$ June, 2020.

Sévigny, A. (2015). "Strategic PR and the value chain: building relationships in social media". Retrieved from http://alexsévigny.ca./?p=2782.

United States Consulate, Lagos (2020). Nigeria 2020 Crime \& Safety Report: Lagos. 